\title{
Age-related changes in children's resource giving: how social categories and fairness considerations influence distribution decisions
}

\author{
Jessica Spence $^{1^{*}}$, Dr. Kana Imuta ${ }^{2}$ \\ ${ }^{1,2}$ School of Psychology, The University of Queensland, Brisbane, Australia \\ *E-mail: jessica.spence@uq.net.au
}

\begin{abstract}
This study investigated children's resource distribution decisions based upon photographs of unfamiliar children that differed in race and accent. Photographs were presented to children with accompanying audio. Seventy-six White 5- to 12-year-old children were given three coins to distribute to pairs of recipients, with an option to be fair by discarding a resource. However, results revealed fairness was not a prominent strategy for children. Children below 7-years-old gave selectively more coins to their race and accent in-group whilst children aged 7- to 8-yearsold gave selectively more coins to their accent in-group only when it was paired with the outgroup race. Children over the age of 9 consistently gave more coins to their accent in-group despite the racial category. It was concluded that for children 9 years of age and older, accent is a stronger social marker than race in guiding their resource distribution decisions.
\end{abstract}

Keywords: Accent; Fairness; In-group bias; Race; Resource distribution

\section{Introduction}

As humans, we have a strong propensity to gravitate towards people who are like ourselves. In fact, as early as 10 months, infants prefer to listen to, endorse and learn from people who share social categories similar to their own (Kinzler, Dupoux, \& Spelke, 2012). By pre-school age, these explicit social preferences based upon social categories are considerably robust (Kinzler \& Spelke, 2011) and extend beyond listening and learning preferences to who they trust and who they want as friends. These social preferences are exhibited based upon salient social categories including gender, race, language and accent, demonstrating that children harbour strong in-group preferences for same-gender (e.g., Shutts, Banaji, \& Spelke, 2010), same-race (e.g., Aboud, Mendelson, \& Purdy, 2003; Levy, 2000; Shutts, Kinzler, Katz, Tredoux, \& Spelke, 2011), same-language (e.g., Kinzler, Shutts, \& Spelke, 2012) and same-accent peers (e.g., Souza, ByersHeinlein, \& Poulin-Dubois, 2013).
Recent evidence on children's social preferences have also examined the relative salience of social categories against one another. For example, research has demonstrated that accent is a more salient marker for children than race (Kinzler, Shutts, DeJesus, \& Spelke, 2009). Kinzler and colleagues (2009) found that children selectively preferred their native-language, native-accent and same-race counterparts, but importantly, when race was pitted against accent, children preferred the other-race, native-accented speaker above the samerace, foreign-accented speaker. These findings highlighted that children weigh up different pieces of information in their social evaluations of others, and that the relative salience of social categories does play a role in their preference decisions.

Whilst the literature on social categories as guiding children's social preferences is rather extensive, it remains uncertain as to the extent to which these 
preferences actually translate into children's behaviour. One area where in-group preferences also seem to manifest in children's behaviour is in resource distribution. However, most studies to date have focused on arbitrarily or minimally assigned groups (e.g., Benozio \& Diesendruck, 2015) and comparisons of resource giving between known versus unknown recipients, establishing children reliably give more resources (both when the resources are their own or not) to friends, family members and class mates, compared to disliked or unfamiliar peers (Lu \& Chang, 2016; Moore, 2009; Paulus \& Moore, 2014). Intuitively, this is not surprising, as researchers have suggested behaving in this way can assist in reinforcing social ties and benefit the overall well-being of the group (Rutland \& Killen, 2017). Perhaps less intuitive but of great interest, is investigating factors which guide children's resource distribution decisions when the recipients are all unfamiliar, differing only by distinct and salient social categories.

Whilst there has been little attention on how these salient social categories solely guide children's resource distribution decisions among unfamiliar recipients (in contrast to guiding their preferences), there have been a few notable studies. Kinzler and Spelke (2011) demonstrated that White 2.5-yearolds did not give more toys to a White target compared with a Black target, and instead were equal in their distribution. Zinser and colleagues (1981) provided evidence that by pre-school age and up to fifth grade children give more resources to their racial in-group. However, in this study, the recipient's racial category was verbally labelled by the experimenter. Kinzler and colleagues (2012) investigated the effect of language in a synonymous task to Kinzler and Spelke (2011), and found that 2.5 -year-olds gave more toys to their language ingroup (native) compared to their language out-group (foreign). Studies have also demonstrated children show preferential resource giving to unfamiliar same-gender peers (e.g., Dunham, Baron, \& Carey, 2011).

More recently, Renno and Shutts (2015) investigated whether children would demonstrate greater resource giving to their racial in-group or opt to be fair in the absence of racial labels by removing labels and providing an egalitarian option for children where a resource could be discarded. This study also investigated the likelihood of preferential resource giving to same-gender peers. It was found that predominantly White 3- to 5-yearold children gave more resources to same-gender and White recipients compared to other-gender and Black children. These findings suggested that children were more strongly guided by the recipient's gender and race category, rather than a desire to be fair. However, resource distribution has been suggested as an important developing ground for children's sense of fairness (Fehr, Bernhard, \& Rockenbach, 2008) and as such, these findings contrast with literature which suggest a sense of fairness and equality forms from early infancy (Geraci \& Surian, 2011; Schmidt \& Sommerville, 2011; Sloane, Baillargeon, \& Premack, 2012), leading children to favour equal resource distribution (e.g., Cooley \& Killen, 2015). According to Fehr and colleagues (2008), most 7- to 8-year-old children are adverse to either advantageous or disadvantageous resource distribution. In fact, research has also demonstrated that children do discard resources in order to be fair (Shaw \& Olson, 2012), but this may be a strategy only older children employ.

Despite the aforementioned extensions in the literature, several questions remain. Firstly, there has only been a handful of research conducted on the role social categories play in guiding children's resource distribution behaviour, so it remains unclear as to what extent their explicit social preferences may also translate into their resource giving behaviour. Secondly, the limited research which has been conducted has largely sampled younger children. Given literature on resource distribution has demonstrated that older children strongly favour fairness (e.g., Fehr et al., 2008; Shaw \& Olson, 2012), it is not yet known how an in-group bias in resource distribution may continue to develop across children's age and how the tension between a desire to be fair and an in-group bias may interact. Thirdly, research has established children are constantly weighing up different pieces 
of information in their social evaluations of others (e.g., Cooley \& Killen, 2015; Killen, 2007; Kinzler $\&$ Dejesus, 2013). As a result, the most recent research on children's resource distribution behaviour places a large focus on the expectations, status perceptions and morality behind children's distribution decisions (e.g., Elenbaas \& Killen, 2016; Elenbaas, Rizzo, Cooley, \& Killen, 2016; Renno \& Shutts, 2015; Rutland \& Killen, 2017). However, there still remains a lack of investigation regarding salient unfamiliar in-group/out-group recipients based upon social category differences. Despite literature demonstrating that accent is a highly salient social marker for children in guiding their preferences and inferences (Kinzler, Corriveau, \& Harris, 2011; Kinzler \& Dejesus, 2013; Souza et al., 2013; Wagner, Dunfield, \& Rohrbeck, 2014), as well as a stronger guiding factor when pitted against race (Kinzler et al., 2009), accent has never been investigated in the context of children's resource giving behaviour nor has the relative saliency of social categories by directly pitting them against one another.

Given the increasingly multicultural and borderless society we live in today, accent provides a discernible indicator of group membership (Kinzler et al., 2009). It is important to understand how outgroup social categories, like one's accent, may be contributing to children's decision to engage in prosocial behaviour (i.e., in resource giving) given the many real-world situations it is present in, such as sharing in the classroom or playground. Understanding whether particular social categories are more salient than another can deepen our understanding regarding the conditions under which in-group bias is present, which may highlight potential strategies in which these biases could be reduced throughout development.

\section{The Current Study}

The current project aims to investigate children's resource distribution behaviour to unfamiliar recipients who differ in racial appearance and accented-ness (either native or foreign), using a method adapted from Renno and Shutts (2015). To directly investigate the relative salience of race and accent, children will experience both congruent pairing of racial appearance and accent (e.g., racial in-group will have an in-group native accent) and incongruent pairing (e.g., racial in-group will have an out-group foreign accent). Children will be asked to distribute three blue plastic chips on every trial to two recipients and will have the option to be fair by discarding a coin on any given trial.

Consistent with previous research (Renno \& Shutts, 2015), it is expected younger children will distribute more resources to members of their in-group than members of their out-group when race and accent are presented congruently. Furthermore, based upon prior literature on social preferences (Kinzler et al., 2009), when race and accent are pitted against one another (i.e., presented incongruently), children are expected to give more resources to their accent ingroup over their race in-group. Finally, older children are expected to discard a resource and favour fairness and therefore be less influenced by in-group bias (Shaw \& Olson, 2012).

\section{Methods}

Participants. A total of 96 children participated in this study, five of which were utilized in pilot testing and were excluded from analysis. Participants were recruited from a primary education school in regional New South Wales, Australia. An additional 15 children were excluded due to clinical diagnoses (8), non-Caucasian appearance (6) and uncooperative behaviour (1). Therefore, the final sample involved 76 White children (21 males: 55 females) aged between 4.65 and 12.09 years $(M=8.41, S D=1.89)$. Participants were split into three age categories for analyses; Less than Seven, Seven and Eight, Nine and Above (see Table 1 for descriptive statistics). 
Table 1

Descriptive Statistics of Less than Seven, Seven and Eight and Nine and Above Age Categories

\begin{tabular}{ccccc}
\hline & $\boldsymbol{N}$ & $\begin{array}{c}\boldsymbol{M} \\
(\boldsymbol{S D})\end{array}$ & $\begin{array}{c}\text { Age } \\
\text { Range } \\
(\text { years) }\end{array}$ & Males \\
\hline Less than Seven & 20 & 6.08 & $4.65-$ & 5 \\
& & $(.58)$ & 6.93 & \\
Seven and Eight & 23 & 7.79 & $7.04-$ & 7 \\
& & $(.53)$ & 8.88 & \\
Nine and Above & 33 & 10.25 & $9.11-$ & 9 \\
& & $(.90)$ & 12.09 & \\
\hline
\end{tabular}

Visual Stimuli. Children viewed photographs of unfamiliar smiling pre-school age children on a computer screen. Photographs were the same stimuli used in Renno and Shutts (2015). Children were presented with eight unique pairs. Two photographs at a time were presented to children on a computer screen; one child in the pair was White and the other was non-White (African American) in appearance. Photographs of children always matched the gender of the participant, in order to control for gender as a confounding in-group marker. The lateral position on the screen of the photographs was counterbalanced, and varied within the experiment. Underneath each photograph on the computer screen rested opaque buckets. An additional black container (the "extra bucket") rested directly in front of the child, in the centre of the two photographs but not directly underneath the screen.

Auditory Stimuli. Auditory stimuli of native versus foreign accented speech were presented along with the photographs. All auditory stimuli were short sentences about animals (e.g., "Bats sleep upside down in trees"), and each child in the presented pair said the same sentence. Whether the native or foreign accent was paired with a White face or nonWhite face was counterbalanced across participants. The non-accented English featured Australian Native voices and the accented English featured voices with a French accent. All audio recordings were of children under 12 years of age.

Trial Type. This study utilized congruent and incongruent combinations of the visual and auditory stimuli. On congruent trials, the White face was presented with the native accent and the non-White face was presented with the foreign accent. On incongruent trials, the White face was presented with the foreign accent and the non-White face was presented with the native accent. Four of the photographic pairs were congruent and four were incongruent with the auditory stimuli. All children participated in both congruent and incongruent trials.

Procedure. A White female experimenter (first author) tested all participants. Test sessions (approximately 15 minutes in length) took place in a small, private room at the school during a normal school day, across a six-day period. Children were randomly assigned to one of two conditions: (1) Congruent Trial presented first, or (2) Incongruent Trial presented first.

Resource Distribution Task. The task was introduced by explaining that the children would be viewing photographs of unfamiliar children who attend school in Brisbane, Australia. The researcher described the three blue plastic chips as "coins" which they were to give out. They were told the coins could be exchanged for prizes and that better prizes would be given to children who have more coins. To make this concept salient, a prize chart on an iPad was shown to children whereby the most prizes featured under the three-coin option.

To explain the task, a photograph of a cartoon Pig and Sheep were used. The researcher demonstrated all possible distribution options with $\mathrm{Mr}$. Pig and Mr. Sheep as potential recipients, specifically explaining which bucket to put each coin depending on who the researcher wanted to allocate the coin to (e.g., "If I wanted to give a coin to Mr. Pig, I would put it in this bucket here because it's underneath Mr. Pig"). It was also explained that coins could be placed in the extra bucket if they did not wish to give the coin to anybody (e.g., "If I didn't want to give this coin to anybody, I would put it here and this means that nobody gets this coin"). Every possible combination was demonstrated to the child. The researcher then asked the child to point to where they would put their coin if they wanted to 
give it to Mr. Pig, Mr. Sheep or nobody respectively, to ensure the child understood what each bucket represented. Children were then invited to demonstrate who they wanted to give their coins.

Once it was satisfied the child understood the task, the photographs and corresponding auditory stimuli were presented. For each presented pair, the researcher said "See these kids? Let's listen to what they sound like". The researcher would then present the left photograph only and say "Let's listen to her/him", followed by presenting the right photograph only and saying "and let's listen to her/him". Following this, both photographs would re-appear on the screen together and the researcher said, "Who do you want to give your coins to?". The child was told that the researcher would be recording on her iPad where they placed their coins so she knew who to give which prizes to, based upon their responses. To assist making the buckets and options salient to the child throughout all trials, the researcher asked at the end of each presented pair for the child to tell her how many coins were in each bucket (e.g., "How many coins for this girl/boy?" for each photograph and "How many coins for nobody?"). This procedure was repeated for the eight presented pairs.

\section{Results}

A 2 (Congruency: Congruent or Incongruent) x 2 (Accent: Native or Foreign) x 2 (Task Order: Congruent First or Incongruent First) x 3 (Age: Less than Seven, Seven and Eight, Nine and Above) Mixed ANOVA was conducted, on the number of coins given to each of the recipients with Congruency and Accent as within-subject factors and Task Order and Age as between-subject factors. This analysis revealed a significant main effect of accent, $F(1,70)=21.68, p<.001, \eta_{p}^{2}=.24$, however this was qualified by a significant Congruency $\mathrm{x}$ Accent $\mathrm{x}$ Age interaction, $F(2,70)=$ 7.31, $p<.01, \eta_{p}^{2}=.17$. Additionally, there was a significant Congruency $\mathrm{x}$ Task Order interaction, $F(1,70)=13.34, p<.001, \eta_{p}^{2}=.16$. All other main effects and interactions were non-significant (see Table 2).
Table 2

Non-significant main effects and interactions for overall Mixed ANOVA

\begin{tabular}{llll}
\hline & $\boldsymbol{F}$ & $\boldsymbol{p}$ & $\boldsymbol{\eta}_{\boldsymbol{p}}^{2}$ \\
\hline Congruency $(1,70)$ & .51 & .478 & .01 \\
Congruency x Age $(1,70)$ & .11 & .900 & .01 \\
Congruency x Accent $(1,70)$ & .06 & .816 & .00 \\
Accent x Task Order $(1,70)$ & .00 & .996 & .00 \\
Accent x Age $(2,70)$ & .08 & .920 & .00 \\
Accent x Task Order x Age $(2$, & 2.48 & .092 & .07 \\
70) & & & \\
Congruency x Task Order x Age & .36 & .701 & .01 \\
$\begin{array}{l}\text { (2, 70) } \\
\text { Congruency x Accent x Task }\end{array}$ & 2.39 & .127 & .03 \\
Order $(1,70)$ & & & \\
Congruency x Accent x Task & 1.68 & .194 & .05 \\
Order x Age (2, 70) & & & \\
\hline
\end{tabular}

To further interpret the interactions, a 2 (Congruency) x 2 (Accent) x 2 (Task Order) Mixed ANOVA was conducted separately for each age group. For the less than seven age group, there was a significant main effect of accent, $F(1,18)=10.56$, $p<.01, \eta_{p}^{2}=.37$, however this was qualified by a Congruency x Accent interaction, $F(1,18)=4.97, p$ $<.05, \eta_{p}^{2}=.22$. Follow up pairwise comparisons revealed that in the congruent trials, there was a significant effect of accent, such that children gave significantly more coins to the native accented, White child $(M=6.85, S E=.53)$ compared to the foreign accented, Black child $(M=3.81, S E=.42)$, $p<.01$. However, in the incongruent trials children did not give significantly more coins to the native accented, Black child $(M=5.29, S E=.40)$ compared to the foreign accented, White child $(M=$ 5.27, $S E=.36), p=.98$. Additionally, there was a significant Congruency x Task Order interaction, $F(1,18)=6.22, p<.05, \eta_{p}^{2}=.26$. Follow up pairwise comparisons revealed that children who received the congruent trial first gave more in the congruent trials $(M=5.38, S E=.17)$ compared to the incongruent trials $(M=4.94, S E=.17)$. Similarly, these revealed that the children who received the incongruent trials first gave more in the incongruent trials $(M=5.50, S E=.22)$ compared to the congruent trials $(M=5.20, S E=.22)$. 
For the seven and eight age group, there was a significant main effect of accent, $F(1,21)=11.85, p$ $<.01, \eta_{p}^{2}=.36$, which was qualified by a Congruency x Accent interaction, $F(1,21)=4.46, p$ $<.05, \eta_{p}^{2}=.18$. Follow up pairwise comparisons revealed that in the incongruent trials, there was a significant effect of accent, such that children gave significantly more coins to the native accented, Black child $(M=6.34, S E=.48)$ compared to the foreign accented, White child $(M=3.69, S E=.38)$, $p<.01$. However, in the congruent trials children did not give significantly more coins to the native accented, White child $(M=5.35, S E=.29)$ compared to the foreign accented, Black child $(M=$ 4.90, $S E=.35), p=.40$.

For the nine and above age group, there was a significant main effect of accent $F(1,31)=5.54, p<$ $.05, \eta_{p}^{2}=.15$, wherein children in general gave more to the native accented child $(M=5.63, S E=$ .31) over the foreign accented child $(M=4.34, S E=$ .26). Additionally, there was a significant Congruency $\mathrm{x}$ Task Order interaction, $F(1,31)=$ 7.05, $p<.05, \eta_{p}^{2}=.16$. Follow up pairwise comparisons revealed that children who received the congruent trials first gave more resources in the congruent trials $(M=4.90, S E=.14)$ compared to incongruent $(M=4.60, S E=.14)$, whereas those who received the incongruent trials first gave more in the incongruent $(M=5.24, S E=.14)$ compared to the congruent $(M=5.05, S E=.15)$. All other main effects and interactions in these analyses were nonsignificant.

\section{Discussion \& Conclusion}

Discussion. This study aimed to investigate how salient social categories, namely someone's race and accent may influence children's resource distribution behaviour towards unfamiliar peers. This study also pitted race against accent to examine whether one social category may be a stronger guiding factor than the other. Further, the project aimed to investigate how children's decision making may change across the primary school period, and whether children would opt to be fair despite social category information.
Consistent with previous research on accent as a salient social marker for guiding children's preferences (Kinzler et al., 2011; Kinzler \& Dejesus, 2013; Souza et al., 2013; Wagner et al., 2014), the findings of this study revealed accent is a highly salient marker for guiding children's resource distribution decisions. Findings also revealed the effect of accent differed as a function of children's age. For example, children below 7years-old exhibited a race and accent bias, whereby children selectively gave more resources to the native-White speaker compared to the foreign-Black speaker. However, they did not selectively give more resources to the native-accented speaker when they did not share their racial category. Further, children aged 7- to 8-years-old did not show selective giving behaviour to either the native-White speaker or the foreign-Black speaker, however, did selectively give more resources to the nativeaccented, Black speaker compared to the foreignWhite speaker. Finally, 9-year-old children and older reliably gave more to the native accented speaker despite the racial category.

Whilst accent exhibited importance for all age levels, accent was found to be a stronger guiding factor when pitted against race only for children aged 9 years and above. This result is consistent with Kinzler and colleague's (2009) conclusions that accent trumps race in the context of children's social preferences. The current study extends upon these findings, demonstrating that accent also acts as a stronger guiding factor for children than race when deciding whom to give resources to. Contrary to Kinzler and colleagues (2009) findings that 5year-olds prefer native-accented speakers even when they do not share racial categories, children below 7-years-old in the present study did not show any clear giving patterns when race and accent were pitted against one another. Therefore, it remains unclear whether race or accent was driving children's selective resource giving in this younger age group. It seems that when there is an obvious ingroup/out-group distinction (i.e., native accent with White child), children reliably give more resources to their in-group, which is consistent with Renno and Shutts (2015) findings that 5-year-olds give 
more to their racial in-group. However, children appear to be confused when race and accent are pitted against one another (i.e., native accent with Black child).

The finding that 7- to 8-year-old children only exhibited in-group bias for the native-accented speaker when it was paired with the racial out-group is curious, as why would children not give to the native-accented speaker when the speaker also shares their racial category? Based upon previous research, it is possible children are considering issues of status and giving more resources to the out-group for pro-social reasons (e.g., Rutland \& Killen, 2017), however, if this were the case, children would be expected to exhibit out-group bias consistently (i.e., give more resources to the foreign-Black speaker compared to the native-White speaker), which did not occur. Therefore, a possible alternative explanation is that children were uncomfortable to exhibit in-group bias when it was most obvious (i.e., native-accent on a White child), however felt more comfortable to give more to the accent in-group when it was paired with the Black child. Research which suggests children over 7years-old mask prejudice in order to avoid disapproval could support this explanation (Quintana \& McKown, 2008). However, it would also be expected that older children would engage in synonymous socially desirable responses. Yet 9year-old children and above were highly consistent in their resource distribution behaviour, reliably giving more to the accent in-group despite the racial category.

Additionally, contrary to expectations and literature which has demonstrated children are attuned to fairness from early infancy (e.g., Geraci \& Surian, 2011; Sloane et al., 2012), fairness and inequality aversion does not seem to be a strategy that children employ in this context. This is inconsistent with literature which suggests older children discard resources in order to be fair (Shaw \& Olson, 2012). However, it was revealed that children were becoming more equitable over time, exhibiting less bias with more trials. It is not clear however, whether this was because children were adapting their strategies over time in order to be fair or simply to try an alternative distribution style.

Taken together, it is clear accent acts as a salient cue for children when deciding whom to give resources to, even above race and a desire to fair. However, its influence does seem to change across the primary school period. The underlying mechanisms through which these changes occur remain unclear and therefore, future research should explore children's reasoning for their distribution decisions.

Finally, it is important to note the sample recruited both strengthened and limited our findings. The sample was recruited from a regional location, with a largely White and monolingual population. As a result, children who participated had minimal contact with out-group ethnicities. On one hand, having children who were not exposed to multiple out-groups meant a lower likelihood of extraneous influences, effectively controlling for exposure. However, the world is increasingly becoming more multicultural and children will frequently find themselves in situations where they interact with out-groups. Therefore, it seems paramount to understand how exposure to out-groups may impact on these findings, and ensure these findings are not culturally specific.

Conclusions. It was revealed that all children demonstrated some degree of in-group bias, distributing more resources to members of their ingroup than members of their outgroup. Furthermore, for children 9 years of age and above, accent was found to be a stronger social marker than race in guiding their distribution decisions. However, contrary to expectations, fairness did not seem to be a prominent strategy for children when distributing resources to unfamiliar peers who differ by race and accent.

Acknowledgements. We would like to thank Maggie Renno and Associate Professor Kristin Shutts for kindly sharing their visual stimuli with us for this project. We would also like to thank the children who participated, their families and teachers. Finally, we would like to thank Sam Sparks for advising us on statistical analysis. 


\section{References}

Aboud, F. E., Mendelson, M. J., \& Purdy, K. T. (2003). Crossrace peer relations and friendship quality. International Journal of Behavioral Development, 27(2), 165-173. doi:10.1080/01650250244000164

Benozio, A., \& Diesendruck, G. (2015). Parochialism in preschool boys' resource allocation. Evolution and Human Behavior, 36(4), 256-264. doi:10.1016/j.evolhumbehav.2014.12.002

Cooley, S., \& Killen, M. (2015). Children's Evaluations of Resource Allocation in the Context of Group Norms. Developmental Psychology, 51(4), 554-563. doi:10.1037/a0038796

Dunham, Y., Baron, A. S., \& Carey, S. (2011). Consequences of "Minimal" Group Affiliations in Children. Child Development, 82(3), 793-811. doi:10.1111/j.14678624.2011.01577.x

Elenbaas, L., \& Killen, M. (2016). How do young children expect others to address resource inequalities between groups? Journal of Experimental Child Psychology, 150, 72-86. doi:10.1016/j.jecp.2016.05.002

Elenbaas, L., Rizzo, M. T., Cooley, S., \& Killen, M. (2016). Rectifying social inequalities in a resource allocation task. Cognition, 155, 176-187. doi:10.1016/j.cognition.2016.07.002

Fehr, E., Bernhard, H., \& Rockenbach, B. (2008). Egalitarianism in young children. Nature, 454(7208), 1079-1083. doi:10.1038/nature07155

Geraci, A., \& Surian, L. (2011). The developmental roots of fairness: infants' reactions to equal and unequal distributions of resources. Developmental Science, 14(5), 1012-1020. doi:10.1111/j.14677687.2011.01048.x

Killen, M. (2007). Children's Social and Moral Reasoning About Exclusion. Current Directions in Psychological Science, 16(1), 32-36. doi:10.1111/j.1467-8721.2007.00470.x

Kinzler, K. D., Corriveau, K. H., \& Harris, P. L. (2011). Children's selective trust in native-accented speakers. Developmental Science, 14(1), 106-111. doi:10.1111/j.1467-7687.2010.00965.x

Kinzler, K. D., \& Dejesus, J. M. (2013). Children's Sociolinguistic Evaluations of Nice Foreigners and Mean Americans. Developmental Psychology, 49(4), 655-664. doi:10.1037/a0028740

Kinzler, K. D., Dupoux, E., \& Spelke, E. (2012). 'Native' Objects and Collaborators: Infants' Object Choices and Acts of Giving Reflect Favor for Native Over Foreign Speakers. Journal of Cognition and Development, 13(1), 67-81. doi:10.1080/15248372.2011.567200
Kinzler, K. D., Shutts, K., DeJesus, J., \& Spelke, E. S. (2009). Accent Trumps Race in Guiding Children's Social Preferences. Social Cognition, 27(4), 623-634. doi:10.1521/soco.2009.27.4.623

Kinzler, K. D., Shutts, K., \& Spelke, E. S. (2012). Languagebased Social Preferences among Children in South Africa. Language Learning and Development, 8(3), 215-232. doi:10.1080/15475441.2011.583611

Kinzler, K. D., \& Spelke, E. S. (2011). Do Infants Show Social Preferences for People Differing in Race? Cognition, 119(1), 1-9. doi:10.1016/j.cognition.2010.10.019

Levy, G. D. (2000). Individual differences in race schematicity as predictors of African American and White children's race-relevant memories and peer preferences. The Journal of Genetic Psychology, 161(4), 400-419. doi:10.1080/00221320009596721

Lu, H. J., \& Chang, L. (2016). Resource allocation to kin, friends, and strangers by 3- to 6-year-old children. Journal of Experimental Child Psychology, 150, 194206. doi:10.1016/j.jecp.2016.05.018

Moore, C. (2009). Fairness in Children's Resource Allocation Depends on the Recipient. Psychological Science, 20(8), 944-948. doi:10.1111/j.14679280.2009.02378.x

Paulus, M., \& Moore, C. (2014). The development of recipientdependent sharing behavior and sharing expectations in preschool children. Developmental Psychology, 50(3), 914-921. doi:10.1037/a0034169

Quintana, S. M., \& McKown, C. (2008). Handbook of race, racism, and the developing child. Hoboken, N.J.: John Wiley \& Sons.

Renno, M. P., \& Shutts, K. (2015). Children's social categorybased giving and its correlates: Expectations and preferences. Developmental Psychology, 51(4), 533543. doi:10.1037/a0038819

Rutland, A., \& Killen, M. (2017). Fair Resource Allocation Among Children and Adolescents: The Role of Group and Developmental Processes. Child Development Perspectives, 11(1), 56-62. doi:10.1111/cdep.12211

Schmidt, M. F. H., \& Sommerville, J. A. (2011). Fairness expectations and altruistic sharing in 15-month-old human infants. PLoS ONE, 6(10). doi:10.1371/journal.pone.0023223

Shaw, A., \& Olson, K. R. (2012). Children discard a resource to avoid inequity. Journal of Experimental Psychology: General, 141(2), 382-395. doi:10.1037/a0025907

Shutts, K., Banaji, M. R., \& Spelke, E. S. (2010). Social categories guide young children's preferences for novel objects. Developmental Science, 13(4), 599610. doi:10.1111/j.1467-7687.2009.00913.x

Shutts, K., Kinzler, K. D., Katz, R. C., Tredoux, C., \& Spelke, E. S. (2011). Race preferences in children: insights 
from South Africa. Developmental Science, 14(6), 1283-1291. doi:10.1111/j.1467-7687.2011.01072.x

Sloane, S., Baillargeon, R., \& Premack, D. (2012). Do Infants Have a Sense of Fairness? Psychological Science, 23(2), 196-204. doi:doi:10.1177/0956797611422072

Souza, A. L., Byers-Heinlein, K., \& Poulin-Dubois, D. (2013). Bilingual and monolingual children prefer native- accented speakers. Frontiers in Psychology, 4(953). doi:10.3389/fpsyg.2013.00953

Wagner, L., Dunfield, K. A., \& Rohrbeck, K. L. (2014). Children's Use of Social Cues When Learning Conventions. Journal of Cognition and Development, 15(3), 479. doi:10.1080/15248372.2013.782459 